\title{
Unusual flavoenzyme catalysis in marine bacteria
}

\author{
Robin Teufel ${ }^{1,2}$, Vinayak Agarwal ${ }^{3}$ \& Bradley S. Moore ${ }^{3,4,5^{*}}$ \\ 'ZBSA, Center for Biological Systems Analysis, University of Freiburg, 79104 Freiburg, Germany \\ ${ }^{2}$ Faculty of Biology, University of Freiburg, 79104 Freiburg, Germany \\ ${ }^{3}$ Center for Oceans and Human Health, Scripps Institution of Oceanography, University of California \\ San Diego, La Jolla, California, 92093, USA. \\ ${ }^{4}$ Center for Marine Biotechnology and Biomedicine, Scripps Institution of Oceanography, University of \\ California San Diego, La Jolla, California, 92093, USA. \\ ${ }^{5}$ Skaggs School of Pharmacy and Pharmaceutical Sciences, University of California San Diego, La \\ Jolla, California 92093, USA. \\ *corresponding author: Moore, Bradley S (Email: bsmoore@ucsd.edu)
}

\begin{abstract}
Ever since the discovery of the flavin cofactor more than 80 years ago, flavin-dependent enzymes have emerged as ubiquitous and versatile redox catalysts in primary metabolism. Yet, the recent advances in the discovery and characterization of secondary metabolic pathways exposed new roles for flavin-mediated catalysis in the generation of structurally complex natural products. Here, we review a selection of key biosynthetic flavoenzymes from marine bacterial secondary metabolism and illustrate how their functional and mechanistic investigation expanded our view of the cofactor's chemical repertoire and led to the discovery of a previously unknown flavin redox state.
\end{abstract}

\section{Introduction}

Various marine organisms, ranging from invertebrates and plants to microbes, produce structurally diverse secondary metabolites with a vast potential for medical application (e.g., as antibiotics or in cancer treatment) [1-3]. Marine bacteria, in particular, were recognized as prolific and underestimated producers of natural product chemicals $[1,4]$, whose biosyntheses frequently require redox tailoring enzymes containing riboflavin (vitamin B2)-derived cofactors in the form of flavin mononucleotide (FMN) and, more frequently, flavin adenine dinucleotide (FAD) [5]. Aside from secondary metabolism, ubiquitous flavoenzymes catalyze numerous essential redox reactions in all domains of life, e.g., in central metabolism, drug metabolism, immune defense, cell signaling, protein folding, DNA repair, apoptosis, light emission, and neural development [6]. The key to the unique reactivity and versatile redox chemistry of the flavin cofactor is the reactive N5-C4a locus of the isoalloxazine ring system, which serves as entry/exit points for electrons as well as a site for covalent adduct formation (Figure 1) [5,7]. Under aerobic conditions, flavins are commonly oxidized $\left(\mathrm{Fl}_{\mathrm{ox}}\right)$, while radical, single-electron reduced neutral (blue, $\mathrm{FlH}^{\circ}$ ) or anionic (red, $\mathrm{Fl}^{-*}$ ) semiquinones (SQs) and two-electron-reduced hydroquinones $\left(\mathrm{Fl}_{\text {red }}\right)$ represent catalytically important redox states (Fig 1) [8-14]. Typical flavin-dependent reactions include the electron exchange between obligatory one-electron (e.g., $\mathrm{Fe}^{\mathrm{III}} / \mathrm{Fe}^{\mathrm{II}}$ ) and two-electron (e.g., NAD(P)H) donors/acceptors or the dehydrogenation of diverse organic substrates (Figure 1). As a rare exception among organic cofactors, protein-bound $\mathrm{Fl}_{\text {red }}$ furthermore enables the efficient reduction of molecular oxygen. $\mathrm{H}_{2} \mathrm{O}_{2}$-forming flavin-dependent oxidases thereby exploit $\mathrm{O}_{2}$ as electron acceptor, as exemplified by NADPH oxidase or monoamine oxidase [13]. Flavin-dependent monooxygenases, by contrast, employ $\mathrm{O}_{2}$-derived covalent flavin oxygen adducts as oxygenating species in the form of the flavin-C4a-peroxide $\left(\mathrm{Fl}_{\mathrm{C} 4 \mathrm{a}[\mathrm{OOH}]}\right)$ [14] or the flavin-N5- 
oxide $\left(\mathrm{Fl}_{\mathrm{N} 5[\mathrm{O}]}\right)[8,9]$ (Figure 1). The electrophilic character of the well-studied transiently produced $\mathrm{Fl}_{\mathrm{C} 4 \mathrm{a}[\mathrm{OOH}]}$ is comparable to other organic hydroperoxides [15] and allows the monooxygenation of organic substrates, for example in the $p$-hydroxybenzoate hydroxylase that catalyzes an electrophilic aromatic substitution reaction [10,16-19]. Enzyme-assisted deprotonation of the hydroperoxide, however, gives rise to a $\mathrm{C} 4 \mathrm{a}-$ peroxyanion that serves as a nucleophilic oxygenating agent, e.g., in Bayer-Villiger type oxidations of ketones to esters [20]. As a further variation of this chemistry, flavin-dependent halogenases exploit the $\mathrm{Fl}_{\mathrm{C} 4 \mathrm{a}[\mathrm{OOH}]}$ as oxidant for the formation of halonium ions, which add to organic substrates through electrophilic substitutions [21,22]. The recently discovered $\mathrm{Fl}_{\mathrm{N} 5[\mathrm{O}]}$ oxygenating species was shown to mediate an oxidative Favorskii-type carbon-carbon rearrangement and may conceivably constitute a versatile redox catalyst, albeit its chemistry is less understood at present (see discussion below) [8,9] (Figure 1) [5]. In this review, we highlight a small selection of recently described marine bacterial flavin-dependent redox tailoring enzymes that adopt crucial roles in the formation of structurally distinct natural products and illustrate the broad diversity of flavin-mediated catalysis. For a comprehensive overview of biosynthetic flavoenzymes, we would like to recommend the excellent work of Walsh and Wencewicz [5].

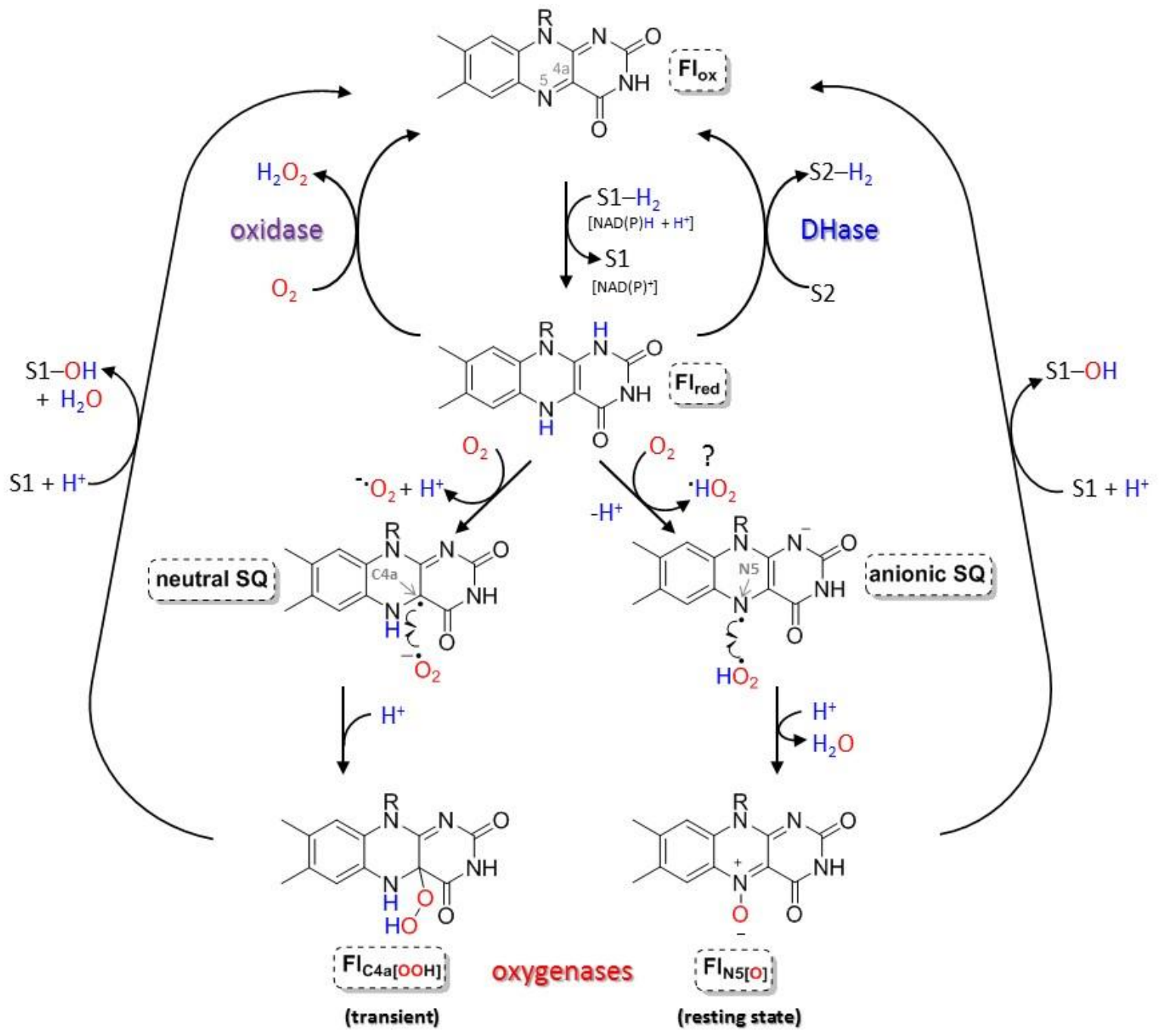

Figure 1. Overview of flavin redox states and catalysis ( $R=$ ribityl-ADP (FAD) or phosphoribityl (FMN)). Oxidases and dehydrogenases (DHase) oxidize organic substrates (S1) and utilize $\mathrm{O}_{2}$ or alternative substrates (S2) for the reoxidation of $\mathrm{FI}_{\text {red }}$ to the catalytically active $\mathrm{Fl}_{\mathrm{ox}}$, respectively. Monooxygenases employ a flavinC4a-(hydro)peroxide or a flavin-N5-oxide for the oxygenation of organic substrates (S1). The radical formation of these oxygenating species proceeds via reduction of $\mathrm{Fl}_{\mathrm{ox}}$ to $\mathrm{FI}_{\text {red }}$ by $\mathrm{NAD}(\mathrm{P}) \mathrm{H}$ or the substrate, which may 
enable the single electron reduction of $\mathrm{O}_{2}$ and subsequent radical coupling of the formed superoxide and the flavin $\mathrm{SQ}$ at the spin density sites $\mathrm{C} 4 \mathrm{a}$ or $\mathrm{N} 5$. Note that the tentative pathway for $\mathrm{Fl}_{\mathrm{N} 5[\mathrm{O}]}$ formation requires further investigation.

\section{Bromination in the biosynthesis of toxic polybromophenols and polybromopyrroles}

The marine environment is an exceptionally rich source of halogenated natural products [23], in particular of brominated natural products that are perhaps exclusively of marine origin. While the participation of flavoenzymes as halogenating catalysts in chlorinated natural product biosynthesis is well established (Figure 2AB) [24], it is surprising to note that physiological marine brominating flavoenzymes, those that cannot catalyze the oxidative incorporation of chlorine [25], had evaded discovery until very recently. Querying the genetic and molecular bases for the biosynthesis of the cytotoxic [26] marine natural product pentabromopseudilin revealed the ' $b m p$ ' gene locus that incorporates two intriguing flavin-dependent brominases [27]. Of these, the enzyme Bmp2 catalyzes the tribromination of L-proline derived pyrrole ring that is acylated to an acyl carrier protein (ACP) (Figure 2C). It is intriguing to note that despite the presence of a 900-fold excess of chloride in sea-water, Bmp2 demonstrates extraordinary halide specificity, in that no chloride incorporation was observed either during in vitro enzymological investigations, or during in vivo pentabromopseudilin production in growth media lacking bromide [27]. Another flavindependent brominase, AltN, shares the remarkable halide selectivity of Bmp2, although the sequence of events leading to the incorporation of the L-tyrosine-derived bromophenyl moiety in the suite of the bromoalterochromide marine natural product lipocyclic peptides remains to be revealed [28]. Identification of Bmp2 and AltN brominases possessing high sequence homology and functional similarity to chlorinases such as Mpy16 (Figure 2C) [29] and SgcC3 [30], respectively, provides avenues to explore the molecular basis for halide specificity in flavin-dependent halogenases. It is thus of note that while postulated halide binding sites in the crystal structures of flavin-dependent chlorinases have been identified that demonstrate resemblance to chloride binding sites in membrane halide transporters [31], their functional relevance remains in question. This is primarily due to the observations that non-halogenating flavoenzymes also bind halide anions in structurally analogous sites (reviewed by Blasiak and Drennan [25]) and that the halide in this position is neither desolvated nor correctly positioned with respect to the $\mathrm{N} 5$ or the $\mathrm{C} 4 \mathrm{a}$ position of the flavin isoalloxazine ring to allow the oxidation of the halide to the halonium ion.

The extraordinary selectivity for bromide is shared by the other flavin-dependent halogenase coded within the bmp gene locus, the phenol brominase Bmp5 [27]. In primary sequence, Bmp5 differs from canonical two-component flavin-dependent halogenases such as Bmp2 that require an exogenous flavin-reductase enzyme to supply the necessary $\mathrm{Fl}_{\text {red }}$. Rather Bmp5 uniquely resembles single-component flavoenzymes with a distinct $\mathrm{NAD}(\mathrm{P}) \mathrm{H}$ binding domain that catalyze the cis reduction of $\mathrm{Fl}_{\mathrm{ox}}$ to $\mathrm{Fl}_{\text {red }}$ [27]. Bmp5 further provides the first example of a flavin-dependent halogenase-mediated electrophilic substitution reaction in which a carboxyl group is lost upon halonium addition rather than a proton, a reaction that has previously been reported for flavin-dependent hydroxylases (Figure 2D) [32]. Hence, Bmp5 likely represents an evolution of function from flavin-dependent oxygenases, an assertion that is supported by the postulated halide oxidation scheme for flavin-dependent halogenases, in which the $\mathrm{Fl}_{\mathrm{C4a}[\mathrm{OOH}]}$ intermediate decomposes to a $\mathrm{Fl}_{\mathrm{C4a}[\mathrm{OX}]}$ species ( $\mathrm{X}=$ halide), that then transfers the halonium via the catalytic lysine side chain to the substrate [21]. The flavoenzyme Bmp5 participates in the formation of natural analogs of some of the most toxic anthropogenic molecules ever synthesized, such as polybrominated diphenyl ethers and dioxins [27,33]. While ubiquitously and abundantly present in the marine environment [34], naturally-produced polybrominated molecules have been detected in the human population as 
well, likely being transferred via our trophic connection to the oceans [35]. Moreover, pentabromopseudilin (Figure 2C) is extraordinarily toxic to brine shrimp, likely representing an ecological role as a feeding deterrent [26]. Similarly, brominated pyrroles have been proposed as chemical cues for coral settlement and metamorphosis [36], thus underscoring the fact that polybrominated molecules generated by the extraordinary selective marine brominases such as Bmp2 and Bmp5 have well defined ecological roles attached to them in the marine metabolome. The mechanism via which marine brominases selectively incorporate bromide in natural product scaffolds against a selection pressure of much higher concentration of chloride in sea-water remains to be elucidated, but is unlikely to be realized by a steric differentiation between chloride and bromide ions within the halogenating enzyme active site. The fact that chlorinating flavin-dependent halogenases catalyze bromination of aromatic substrates but brominases do not catalyze chlorination reactions hints towards differential dehydration penalties for chloride and bromide ions, together with different oxidation potentials for the generation of halonium intermediates as the selectivity filter determining the halide specificity for halogenating enzyme catalysts.

a

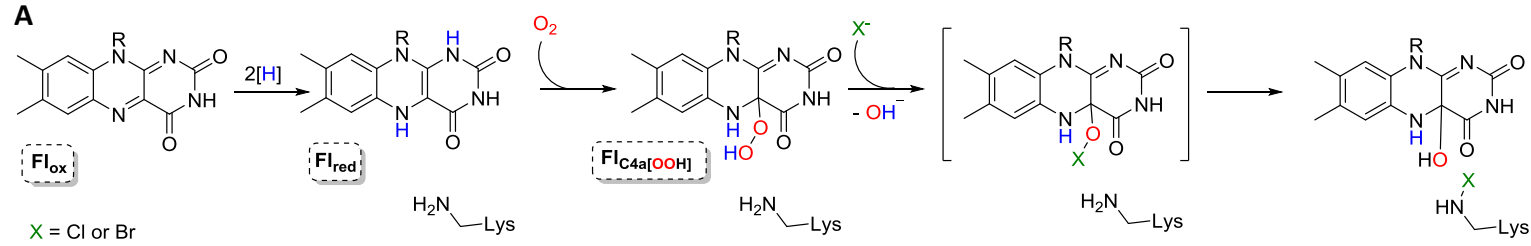

B

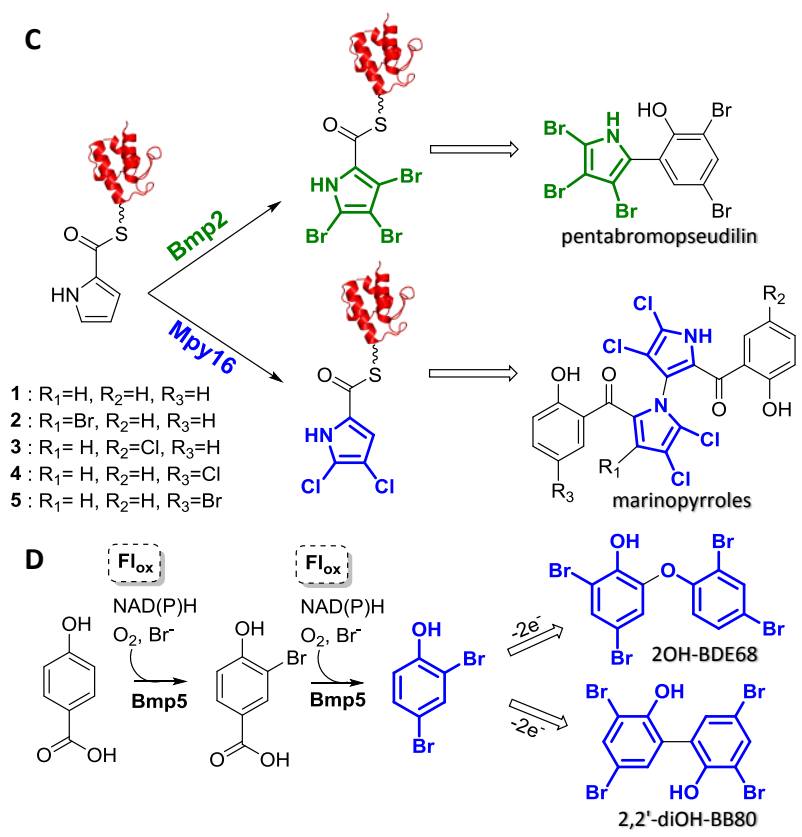

Figure 2. Flavin-dependent halogenation chemistry. (A) Reaction mechanism for flavin-dependent halogenases. Flavin-dependent halogenases are $\mathrm{O}_{2}$-dependent enzymes, and the first half of the reaction is identical to flavin-dependent oxygenases, in which the transient $\mathrm{FI}_{\mathrm{C} 4 a[\mathrm{OOH}]}$ transient species is generated. This decomposes to a postulated $\mathrm{Fl}_{\mathrm{CA}[0 \mathrm{OX}]}$ transition state with the concomitant release of a water molecule, whereupon the halonium is transferred to an appropriately positioned catalytic lysine side chain. The lysine side chain halo-amine is postulated to be the active halogenating agent. Note that in canonical flavindependent halogenases, $\mathrm{FI}_{\text {red }}$ is provided by a partner flavin-reductase enzyme. (B) Active site representation of the canonical flavin-dependent halogenase PrnA (37) in complex with cofactor FAD (in stick-ball representation with carbon atoms colored yellow), a chloride ion (in sphere representation colored orange), and the product 6-chloro-tryptophan (in stick ball representation with carbon atoms colored blue). Also shown 
are the haloamine bearing lysine side chain, the catalytic base glutamate side chain that abstracts the proton subsequent to chloronium addition to the substrate, and the water molecules in close proximity to the chloride ion. The $\mathrm{C} 4$ and $\mathrm{N} 5$ positions of the flavin isoalloxazine ring are marked. (C) Reactions catalyzed by Bmp2 and Mpy16. (D) Two-step reaction for Bmp5 leading to the formation of 2,4-dibromophenol from $p$ hydroxybenzoic acid. 2,4-dibromophenol further undergoes oxidative coupling to generate bioaccummulative and persistent pollutant natural products such as the polybrominated diphenyl ethers 2OH-BDE68 and biphenyl-2,2'-diOH-BB80.

\section{Pyrrolizine ring formation in chlorizidine A biosynthesis}

The berberine bridge enzyme (BBE)-like flavin oxidase Clz9 likely contains a bicovalently attached FAD and was recently shown to mediate an unusual oxidative cyclization reaction in the biosynthesis of the tetrachlorinated alkaloid chlorizidine A by the marine Streptomyces sp. CNH-287 [38]. Chlorizidine A features rare pyrroloisoindolone and pyrrolizine rings connected through a single $\mathrm{C}-\mathrm{C}$ bond and its assembly requires an extraordinary interplay between enzymes originating from polyketide and fatty acid biosynthesis [38]. In vitro studies confirmed that the final pathway step, however, is catalyzed by the redox tailoring enzyme $\mathrm{Clz} 9$ and involves the formation of an intramolecular $\mathrm{C}-\mathrm{N}$ bond between $\mathrm{C} 13$ and the pyrrole nitrogen of prechlorizidine $\mathrm{A}$, thus giving rise to the pyrrolizine ring (Figure 3A) [38]. Flavin oxidases generally catalyze (non-oxygenating) 2electron oxidation reactions of organic substrates and employ $\mathrm{O}_{2}$ for the subsequent required reoxidation of $\mathrm{Fl}_{\text {red }}$ to the catalytically active $\mathrm{Fl}_{\text {ox }}$. The stereoselective, oxidative cyclization reaction in chlorizidine biosynthesis may therefore proceed via hydride abstraction from prechlorizidine $\mathrm{A}$ by the electrophilic $\mathrm{N} 5$ of $\mathrm{Clz}$-bound $\mathrm{Fl}_{\mathrm{ox}}$, before the intermediate is attacked by the nucleophilic pyrrole-nitrogen to yield chlorizidine A (Figure 3A). The bicovalent link of the flavin with Clz9 possibly increases the oxidative power of the $\mathrm{Fl}_{\mathrm{ox}}$ and enables this unfavorable reaction, as has been similarly demonstrated in other cases [39-41]. The proposed mechanism is reminiscent of other BBE-family members [42], yet structural and detailed mechanistic studies are required to further illuminate this intriguing flavindependent cyclization reaction.

\section{Radical indoloterpene coupling and cycloether formation}

Until recently, it was assumed that flavin-dependent oxygenases employ a universal oxygen activation pathway, which leads to the formation of $\mathrm{C} 4 \mathrm{a}$-bound peroxides. One possible exception may be realized by $\mathrm{XiaH}$, a homologue of flavin-dependent aromatic ring hydroxylases that is essential for the conversion of the indolosesquiterpene xiamycin into oxiamycin and various bixiamycins in bacterial endophytes of mangrove trees (Figure 3B) $[43,44]$. The dimerization of xiamycin to the bixiamycins was proposed to proceed via radical $\mathrm{N}-\mathrm{C}$ and $\mathrm{N}-\mathrm{N}$ aryl-aryl coupling reactions, in which $\mathrm{XiaH}-\mathrm{Fl}_{\mathrm{ox}}$-catalyzed single-electron oxidation of xiamycin gives rise to xiamycin-N1-radicals that undergo homocoupling at the spin density sites N1, C6, or C21 (Figure 3B). Such radical aryl-aryl coupling chemistry is highly unusual for flavoenzymes and generally a domain of cytochrome P450 enzymes [45]. In addition, $\mathrm{XiaH}$ exhibited oxygenase activity and enabled the formation of the cycloether oxiamycin through insertion of an oxygen atom between $\mathrm{C} 11$ and $\mathrm{C} 12$ of xiamycin. The authors suggested that in this alternative route, the flavin SQ species (produced by the initial xiamycin oxidation step) may be reoxidized to $\mathrm{Fl}_{\mathrm{ox}}$ through molecular oxygen, which produces a reactive superoxide that reacts with the xiamycin-radical at $\mathrm{C} 11$ to afford a transient xiamycin-C11-hydroperoxide. The subsequent peroxide-mediated ring expansion to tetrahydrooxepin under elimination of water would additionally require a (possibly $\mathrm{NAD}(\mathrm{P}) \mathrm{H}$-dependent) reduction step and complete the pathway to oxiamycin [44]. XiaH may 
thus represent an unusual member of the "internal monooxygenases" that use their substrate as electron donor for the activation of oxygen. Related flavin-dependent oxygenases, however, commonly use $\mathrm{NAD}(\mathrm{P}) \mathrm{H}$ as an external electron source, which $\mathrm{XiaH}$ may instead expend for the required reduction step en route to oxiamycin [44]. Direct evidence for the intriguing XiaH catalytic mechanism was not presented, yet the treatment of xiamyxin with a radical forming agent allowed the biomimetic generation of several bixiamycins as well as oxiamycin and thereby significantly substantiated a radical process [44].

A

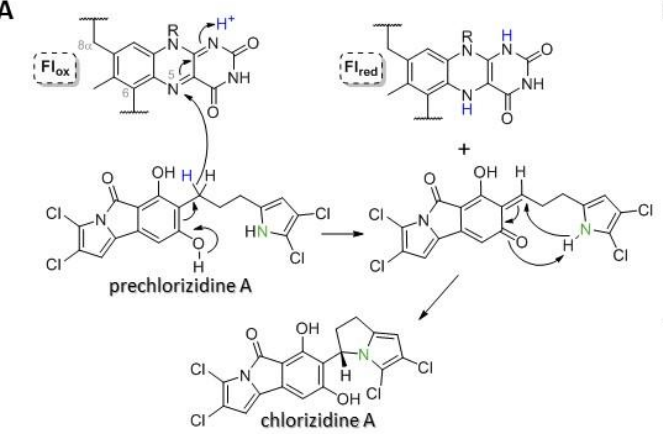

c

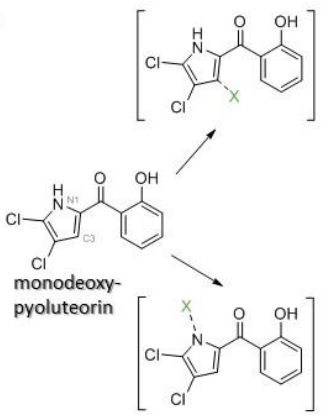

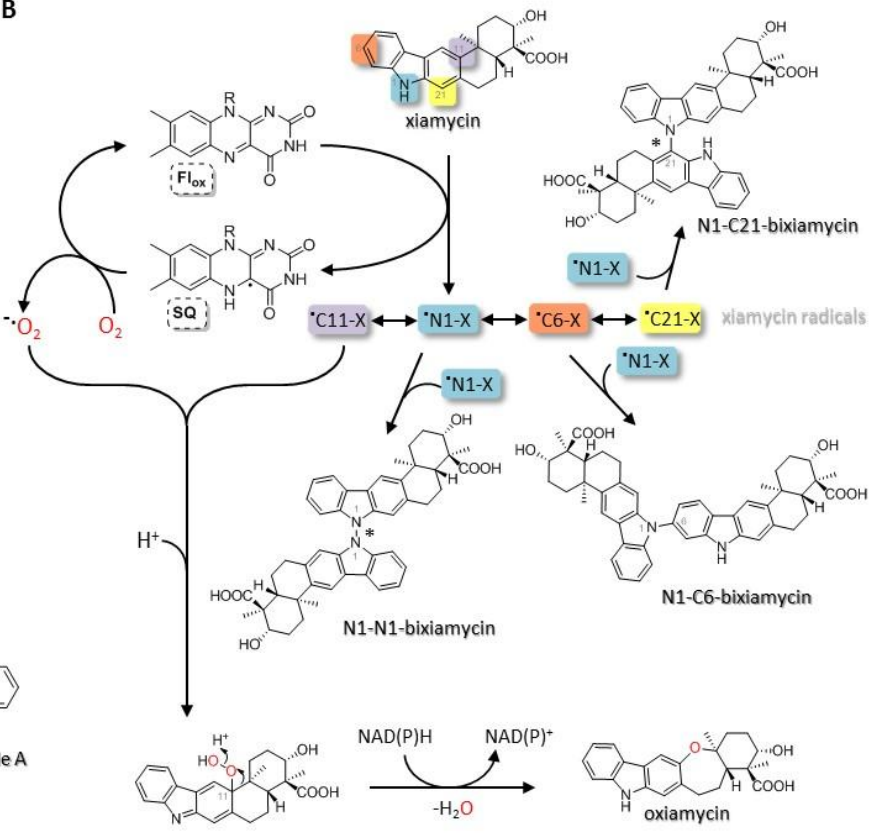

Figure 3. Selected flavin-catalyzed coupling reactions. (A) Proposed pyrrolizine ring formation by Clz9. Prechlorizidine $\mathrm{A}$ is dehydrogenated by $\mathrm{Cl} z \mathrm{~g} 9-\mathrm{Fl}_{\mathrm{ox}}$, followed by the regio- and stereoselective pyrrolizine-forming cyclization reaction through pyrrole coupling that affords chlorizidine A. The C8 $\alpha$ and $\mathrm{C} 6$ of the flavin cofactor are likely covalently linked to His99 and $\mathrm{Cys} 157$ of $\mathrm{Clz9}$, respectively. Oxidation of $\mathrm{FI}_{\text {red }}$ by $\mathrm{O}_{2}$ regenerates $\mathrm{Fl}_{\text {ox }}$ (not shown). (B) Tentative mechanism for the XiaH-catalyzed radical xiamycin coupling and oxiamycin formation. XiaH is proposed to catalyze the single-electron oxidation of the indoloterpenoid xiamycin, which then undergoes various radical dimerization reactions to bixiamycins or reacts with superoxide and possibly $\mathrm{NAD}(\mathrm{P}) \mathrm{H}$ to oxiamycin. The asterisks indicate a mixture of the respective atropoisomers with stable $P$ - and $M$ configurations. (C) Proposed mechanism for C-N bond formation by the Mpy10-Mpy11 enzyme pair. Cryptic halogenation at either the $\mathrm{C} 3$ or the N1 positions of the monodeoxypyoluteorin monomer leads to the formation of a trihalo intermediate that undergoes nucleophilic halide displacement to yield the marinopyrrole dimer. Note that a radical mechanism is plausible too.

Another probable example of atroposelective biaryl coupling catalyzed by a flavoenzyme is provided by the postulated biosynthetic scheme for the marinopyrrole suite of halogenated marine natural products $[34,46]$. Using genetic experiments, it was demonstrated that two flavoenzymes coded by the genes mpyl0 and mpy 11 , along with the flavin-reductase coded by the gene mpyl, catalyze the coupling of monomeric monodeoxypyoluteorin to marinopyrrole A (Figure 3C) [34]. An in vitro reconstitution of the activity of Mpy10 and Mpy11 has not been reported as yet, consequently, physiological intermediates in the C-N bond formation event have not been elucidated. However, as Mpy10 and Mpy11 possess high sequence similarity to flavin-dependent halogenases, and because the coupling is dependent on the presence of the flavin-reductase Mpyl, two possible routes leading to the formation of the $\mathrm{C}-\mathrm{N}$ bond have been proposed. In each of the scenarios, cryptic trihalo-pyrrole 
intermediates have been invoked that undergo a second electrophilic substitution reaction to yield the final product. Cryptic halogenated intermediates that, in essence, act as intra- or intermolecular alkylating agents by nucleophilic displacement of the halide have been proposed in the biosynthesis of other marine natural products such as curacin [47]. The fact that these intermediates have not been observed when either or both genes mpyl0 and mpyl1 were expressed in vivo (in the presence of mpyl and fed monodeoxypyoluteorin substrate), points to the fact that the trihalo intermediates might not be released prior to the $\mathrm{C}-\mathrm{N}$ bond formation by the catalytic enzyme complex. A radical coupling mechanism similar to xiamycin formation, however, cannot be ruled out. Notably, in contrast to the formation of bixiamycins, only a single atropoisomer is generated in high selectivity by the Mpy10-Mpy11 enzyme complex.

\section{A flavin-N5-oxide-mediated oxidative carbon-carbon rearrangement}

The flavoenzyme EncM is another remarkable internal monooxygenase that is involved in the biosynthesis of the unusual polyketide antibiotic enterocin in Streptomyces maritimus [48]. EncM is a structural homologue of flavin-dependent oxidases/dehydrogenases (rather than oxygenases) and was first shown to single-handedly catalyze an oxidative Favorskii-type carbon-carbon rearrangement that entails the formation of a tricyclic caged core, the structural hallmark of enterocin (Figure 4) [49]. Recently, detailed biochemical studies revealed EncM's unprecedented oxygen reactivity and led to the surprising discovery of the $\mathrm{Fl}_{\mathrm{N} 5[\mathrm{O}]}$ cofactor [9]. ${ }^{18} \mathrm{O}$-labeling studies furthermore established $\mathrm{Fl}_{\mathrm{N} 5[\mathrm{O}]}$ as the oxygenating species in the EncM-catalyzed reaction, which formally involves a hydroxylation-dehydrogenation dual oxidation of the linear, acyl carrier protein (EncC) bound octaketide substrate that triggers the Favorskii rearrangement [9]. The $\mathrm{Fl}_{\mathrm{N} 5[\mathrm{O}]}$ species constitutes a superoxidized flavin that is stably maintained under aerobic conditions in contrast to the transiently formed $\mathrm{Fl}_{\mathrm{C} 4 \mathrm{a}[\mathrm{OOH}]}$. Both oxygenating species may be produced,

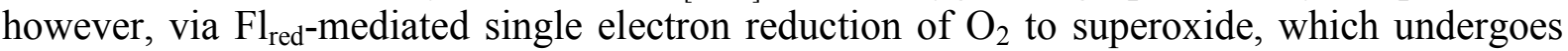
rapid radical coupling with the concomitantly formed SQ species (Figure 1). The nature of the radical SQ intermediate is controlled by the protein-based microenvironment and might be pivotal for the regiospecific coupling at the high spin-density sites $\mathrm{C} 4 \mathrm{a}$ (producing the $\mathrm{Fl}_{\mathrm{C4}[\mathrm{a}[\mathrm{OOH}]}$ ) or $\mathrm{N} 5$ (producing the $\mathrm{Fl}_{\mathrm{N} 5[\mathrm{O}]}$ ) of the neutral and anionic SQ, respectively [8]. The oxygenation pathway may involve single-electron transfer and radical coupling to produce the hydroxylated intermediate (Figure 4, step I, route a) or, alternatively, be envisaged as a nucleophilic attack of the substrate enolate on the electrophilic oxoammonium resonance form of the $\mathrm{Fl}_{\mathrm{N} 5[\mathrm{O}]}$ (step I, route b) [9]. The following dehydrogenation of the introduced hydroxyl by $\mathrm{N} 5$ of $\mathrm{Fl}_{\text {ox }}$ affords $\mathrm{Fl}_{\text {red }}$ independent of external reductants (step II) and allows the subsequent regeneration of the $\mathrm{Fl}_{\mathrm{N} 5[\mathrm{O}]}$ in the presence of $\mathrm{O}_{2}$ (step III). Notably, the $\mathrm{Fl}_{\mathrm{N} 5[\mathrm{O}]}$ likely represents a less precarious oxygenating species compared to the flavin-C4a-peroxide, which readily collapses to $\mathrm{Fl}_{\mathrm{ox}}$ and toxic $\mathrm{H}_{2} \mathrm{O}_{2}$. Two strategies for preventing the formation of $\mathrm{H}_{2} \mathrm{O}_{2}$ are known from flavin-C4a-peroxide-dependent oxygenases. "Cautious" oxygenases generate the $\mathrm{Fl}_{\mathrm{C} 4 \mathrm{a}[\mathrm{OOH}]}$ only in the presence of substrate, whereas "bold" oxygenases produce and stabilize this intrinsically labile species (even in the absence of substrate), resulting in half-lives of up to several minutes [14]. EncM, by this analogy, might be considered a "smart" flavin-dependent oxygenase that employs a safe form of activated oxygen adapted for reactive substrates. To date, EncM is the only reported enzyme utilizing a $\mathrm{Fl}_{\mathrm{N} 5[\mathrm{O}]}$, possibly because this newly recognized flavin redox state has been overlooked in the past [8]. Since the $\mathrm{Fl}_{\mathrm{N} 5[\mathrm{O}]}$ may conceivably participate in nucleophilic, electrophilic, and radical oxidation reactions, we posit that the discovery of additional $\mathrm{Fl}_{\mathrm{N} 5[\mathrm{O}]}$-dependent enzymes may be forthcoming [8]. 


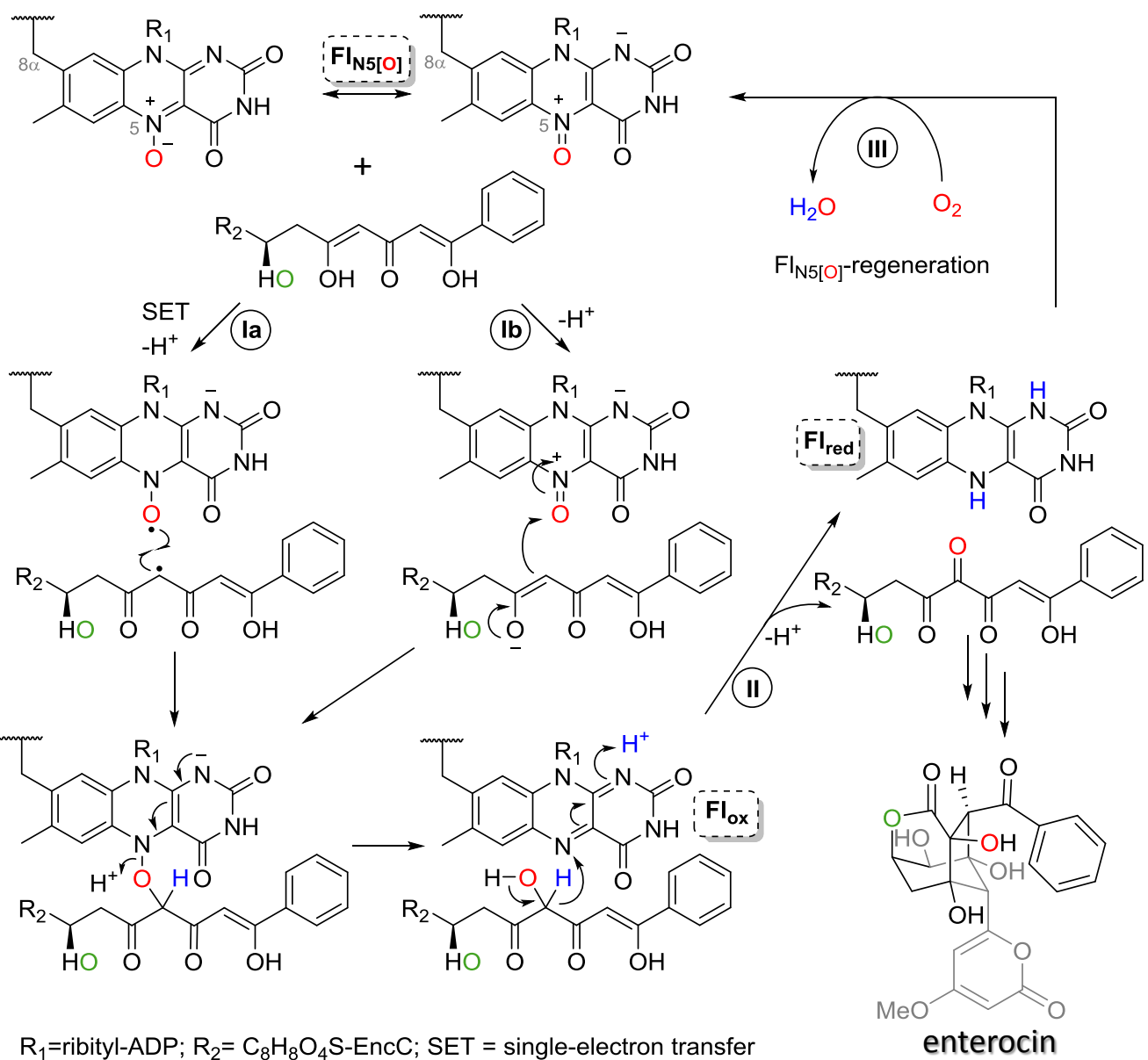

Figure 4. Proposed EncM- $\mathrm{FI}_{\mathrm{N5}[\mathrm{O}]}$-catalyzed poly( $\left.\beta\right)$-ketone dual oxidation. The $\mathrm{C} 8 \alpha$ of the flavin cofactor is covalently attached to the His78 of EncM. Note that the EncM-mediated Favorskii rearrangement and subsequent reactions required for enterocin-formation are not shown. The steps indicated by the roman numerals are discussed in the main text. For details of the $\mathrm{Fl}_{\mathrm{N} 5[0]}$-regeneration pathway see Figure 1 .

\section{Concluding remarks}

The importance of the flavin cofactor for countless redox reactions was recognized long ago, albeit mechanistic studies were heavily focused on a moderate assortment of primary metabolic flavoenzymes. While this granted deep insight into many aspects of flavindependent catalysis, the more recent detailed biochemical characterization of secondary metabolic pathways has proven a true treasure trove for flavin enzymology and unearthed a broader catalytic diversity, as exemplified by the discovery of the $\mathrm{Fl}_{\mathrm{N} 5[\mathrm{O}]}$ redox state [8,9].The astonishing redox versatility of flavoenzymes appears ideally suited for secondary metabolism, nature's biosynthetic tinkering ground, and significantly contributes to the vast chemical diversity of natural products via functionalization (e.g. bromination, hydroxylation) or substrate activation reactions (e.g. dehydrogenation). Notably, a large number of prokaryotic biosynthetic pathways remain untapped [50], particularly in marine bacteria that constitute an underexplored source of natural product molecules [1,4]. Already, flavoenzymes are being used as cues to mine complex metagenomes, both genetically [51], as well as computationally [27] in the search for biosynthetic gene loci for marine natural products of pharmaceutical interest. Future studies of such biosynthetic routes will therefore not cease to unveil novel flavin-dependent enzyme reactions and ultimately provide a more complete picture of the cofactor's intricate chemistry. 


\section{Acknowledgments}

We are grateful to our many colleagues and collaborators who have passionately contributed to our study of marine bacterial flavoproteins. Our work on the biosynthesis of flavoproteinbased marine natural products has been generously supported by grants from the NIH (R01AI047818, P01-ES021921) and NSF (OCE-1313747) and fellowships from the DFG (TE 931/1-1 and TE 931/2-1 to R. T.) and Helen Hay Whitney Foundation (to V. A.).

\section{References and recommended reading}

Papers of particular interest, published within the period of review, have been highlighted as:

* of special interest

** of outstanding interest

1. Lane AL, Moore BS: A sea of biosynthesis: marine natural products meet the molecular age. Nat Prod Rep 2011, 28:411-428.

2. Molinski TF, Dalisay DS, Lievens SL, Saludes JP: Drug development from marine natural products. Nat Rev Drug Discov 2009, 8:69-85.

3. Blunt JW, Copp BR, Keyzers RA, Munro MHG, Prinsep MR: Marine natural products. Nat Prod Rep 2015, 32:116-211.

4. Piel J: Metabolites from symbiotic bacteria. Nat Prod Rep 2009, 26:338-362.

5. Walsh CT, Wencewicz TA: Flavoenzymes: Versatile catalysts in biosynthetic pathways. Nat Prod Rep 2012, 30:175-200.

6. Fagan RLP, B. A. : Flavin-Dependent Enzymes. Edited by: Elsevier; 2010. vol Ch. 3 in Comprehensive Natural Products II, vol. 7 (Begley, T. P., ed.).]

7. Walsh C: Flavin coenzymes - at the crossroads of biological redox. Acc Chem Res 1980, 13:148-155.

8. Teufel R, Stull F, Meehan MJ, Michaudel Q, Dorrestein PC, Palfey B, Moore BS: Biochemical

* Establishment and Characterization of EncM's Flavin-N5-oxide Cofactor. J Am Chem Soc 2015, 137:8078-8085.

Evidence for the flavin-N5-oxide by isotope labeling and mass spectrometry as well as proposed enzymatic synthesis.

9. Teufel R, Miyanaga A, Michaudel Q, Stull F, Louie G, Noel JP, Baran PS, Palfey B, Moore BS:

** Flavin mediated dual oxidation controls an enzymatic Favorskii-type rearrangement. Nature 2013, 503:552-556.

First study showing the novel flavin-N5-oxide redox state and its proposed catalytic function

10. Massey V: Activation of molecular oxygen by flavins and flavoproteins. J Biol Chem 1994, 269:22459-22462.

11. Massey V, Hemmerich P: Active-site probes of flavoproteins. Biochem Soc Trans 1980, 8:246-257.

12. Smitherman C, Gadda G: Evidence for a transient peroxynitro acid in the reaction catalyzed by nitronate monooxygenase with propionate 3-nitronate. Biochemistry 2013, 52:26942704.

13. Chaiyen $\mathrm{P}$, Fraaije MW, Mattevi A: The enigmatic reaction of flavins with oxygen. Trends Biochem Sci 2012, 37:373-380.

14. Palfey BA, McDonald CA: Control of catalysis in flavin-dependent monooxygenases. Arch Biochem Biophys 2010, 493:26-36.

15. Bruice TC: Oxygen-flavin chemistry. Isr J Chem 1984, 24:54-61.

16. Entsch B, Ballou DP: Purification, properties, and oxygen reactivity of p-hydroxybenzoate hydroxylase from Pseudomonas aeruginosa. Biochim Biophys Acta 1989, 999:313-322.

17. Entsch $B$, Ballou DP, Massey V: Flavin-oxygen derivatives involved in hydroxylation by $\mathbf{p}$ hydroxybenzoate hydroxylase. J Biol Chem 1976, 251:2550-2563. 
18. Entsch B, Cole L, Ballou DP: Protein dynamics and electrostatics in the function of $\mathbf{p}$ hydroxybenzoate hydroxylase. Arch Biochem Biophys 2005, 433:297-311.

19. Ballou DP, Entsch B, Cole LJ: Dynamics involved in catalysis by single-component and twocomponent flavin-dependent aromatic hydroxylases. Biochem Biophys Res Commun 2005, 338:590-598.

20. Ryerson CC, Ballou DP, Walsh C: Mechanistic studies on cyclohexanone oxygenase. Biochemistry 1982, 21:2644-2655.

21. Yeh E, Blasiak LC, Koglin A, Drennan CL, Walsh CT: Chlorination by a long-lived intermediate in the mechanism of flavin-dependent halogenases. Biochemistry 2007, 46:1284-1292.

22. Yeh E, Garneau S, Walsh CT: Robust in vitro activity of RebF and RebH, a two-component reductase/halogenase, generating 7-chlorotryptophan during rebeccamycin biosynthesis. Proc Natl Acad Sci USA 2005, 102:3960-3965.

23. Gribble GW: Naturally Occurring Organohalogen Compounds - A Comprehensive Update, vol 91: Springer Vienna; 2010.

24. Neumann CS, Fujimori DG, Walsh CT: Halogenation strategies in natural product biosynthesis. Chem Biol 2008, 15:99-109.

25. Blasiak LC, Drennan CL: Structural perspective on enzymatic halogenation. Acc Chem Res 2009, 42:147-155.

26. Neu AK, Mansson M, Gram L, Prol-Garcia MJ: Toxicity of bioactive and probiotic marine bacteria and their secondary metabolites in Artemia sp. and Caenorhabditis elegans as eukaryotic model organisms. Appl Environ Microbiol 2014, 80:146-153.

27. Agarwal V, El Gamal AA, Yamanaka K, Poth D, Kersten RD, Schorn M, Allen EE, Moore BS:

** Biosynthesis of polybrominated aromatic organic compounds by marine bacteria. Nat Chem Biol 2014, 10:640-647.

Discovery and characterization of first marine flavin-dependent brominases.

28. Ross AC, Gulland LE, Dorrestein PC, Moore BS: Targeted capture and heterologous expression of the Pseudoalteromonas alterochromide gene cluster in Escherichia coli represents a promising natural product exploratory platform. ACS Synth Biol 2015, 4:414420.

29. Yamanaka K, Ryan KS, Gulder TA, Hughes CC, Moore BS: Flavoenzyme-catalyzed atropo* selective N,C-bipyrrole homocoupling in marinopyrrole biosynthesis. J Am Chem Soc 2012, 134:12434-12437.

Evidence for enzymatic N,C-bipyrrole homocoupling through the interaction of two flavin-dependent halogenases

30. Lin S, Van Lanen SG, Shen B: Regiospecific chlorination of (S)-beta-tyrosyl-S-carrier protein catalyzed by SgcC3 in the biosynthesis of the enediyne antitumor antibiotic C-1027. J Am Chem Soc 2007, 129:12432-12438.

31. Zomot E, Bendahan A, Quick M, Zhao Y, Javitch JA, Kanner BI: Mechanism of chloride interaction with neurotransmitter:sodium symporters. Nature 2007, 449:726-730.

32. Eppink MH, Boeren SA, Vervoort J, van Berkel WJ: Purification and properties of 4hydroxybenzoate 1-hydroxylase (decarboxylating), a novel flavin adenine dinucleotidedependent monooxygenase from Candida parapsilosis CBS604. J Bacteriol 1997, 179:66806687.

33. Agarwal V, Moore BS: Enzymatic synthesis of polybrominated dioxins from the marine environment. ACS Chem Biol 2014, 9:1980-1984.

34. Agarwal V, Li J, Rahman I, Borgen M, Aluwihare LI, Biggs JS, Paul VJ, Moore BS: Complexity of naturally produced polybrominated diphenyl ethers revealed via mass spectrometry. Environ Sci Technol 2015, 49:1339-1346.

35. Wiseman SB, Wan Y, Chang H, Zhang X, Hecker M, Jones PD, Giesy JP: Polybrominated diphenyl ethers and their hydroxylated/methoxylated analogs: environmental sources, metabolic relationships, and relative toxicities. Mar Pollut Bull 2011, 63:179-188. 
36. Sneed JM, Sharp KH, Ritchie KB, Paul VJ. The chemical cue tetrabromopyrrole from a biofilm bacterium induces settlement of multiple Caribbean corals. Proc Biol Sci 2014, 281 (1786).

37. Dong CJ, Flecks S, Unversucht S, Haupt C, van Pee KH, Naismith JH: Tryptophan 7-halogenase (PrnA) structure suggests a mechanism for regioselective chlorination. Science 2005, 309:2216-2219.

38. Mantovani SM, Moore BS: Flavin-Linked Oxidase Catalyzes Pyrrolizine Formation of Dichloropyrrole-Containing Polyketide Extender Unit in Chlorizidine A. J Am Chem Soc 2013, 135:18032-18035.

39. Fraaije MW, van den Heuvel RHH, van Berkel WJH, Mattevi A: Covalent flavinylation is essential for efficient redox catalysis in vanillyl-alcohol oxidase. J Biol Chem 1999, 274:35514-35520.

40. Blaut M, Whittaker K, Valdovinos A, Ackrell BAC, Gunsalus RP, Cecchini G: Fumarate reductase mutants of Escherichia coli that lack covalently bound flavin. J Biol Chem 1989, 264:13599-13604.

41. Huang C-H, Winkler A, Chen C-L, Lai W-L, Tsai Y-C, Macheroux P, Liaw S-H: Functional roles of the 6-S-cysteinyl, 8alpha-N1-histidyl FAD in glucooligosaccharide oxidase from Acremonium strictum. J Biol Chem 2008, 283:30990-30996.

42. Winkler A, Lyskowski A, Riedl S, Puhl M, Kutchan TM, Macheroux P, Gruber K: A concerted mechanism for berberine bridge enzyme. Nat Chem Biol 2008, 4:739-741.

43. Ding L, Munich J, Goerls H, Maier A, Fiebig HH, Lin WH, Hertweck C: Xiamycin, a pentacyclic indolosesquiterpene with selective anti-HIV activity from a bacterial mangrove endophyte. Bioorg Med Chem Lett 2010, 20:6685-6687.

44. Baunach M, Ding L, Bruhn T, Bringmann G, Hertweck C: Regiodivergent NC and NN Aryl

* Coupling Reactions of Indoloterpenes and Cycloether Formation Mediated by a Single Bacterial Flavoenzyme. Angew Chem Int Ed 2013, 52:9040-9043.

Evidence for unusual radical coupling and oxygenation chemistry by a multitasking flavoenzyme

45. Aldemir H, Richarz R, Gulder TAM: The Biocatalytic Repertoire of Natural Biaryl Formation. Angew Chem Int Ed 2014, 53:8286-8293.

46. Hughes CC, Prieto-Davo A, Jensen PR, Fenical W: The marinopyrroles, antibiotics of an unprecedented structure class from a marine Streptomyces sp. Org Lett 2008, 10:629-631.

47. Gu L, Wang B, Kulkarni A, Geders TW, Grindberg RV, Gerwick L, Hakansson K, Wipf P, Smith $\mathrm{JL}$, Gerwick WH, et al.: Metamorphic enzyme assembly in polyketide diversification. Nature 2009, 459:731-735.

48. Piel J, Hertweck C, Shipley PR, Hunt DM, Newman MS, Moore BS: Cloning, sequencing and analysis of the enterocin biosynthesis gene cluster from the marine isolate 'Streptomyces maritimus': evidence for the derailment of an aromatic polyketide synthase. Chem Biol 2000, 7:943-955.

49. Xiang L, Kalaitzis JA, Moore BS: EncM, a versatile enterocin biosynthetic enzyme involved in Favorskii oxidative rearrangement, aldol condensation, and heterocycle-forming reactions. Proc Natl Acad Sci USA 2004, 101:15609-15614.

50. Cimermancic P, Medema MH, Claesen J, Kurita K, Brown LCW, Mavrommatis K, Pati A, Godfrey PA, Koehrsen M, Clardy J, et al.: Insights into Secondary Metabolism from a Global Analysis of Prokaryotic Biosynthetic Gene Clusters. Cell 2014, 158:412-421.

51. Bayer K, Scheuermayer M, Fieseler L, Hentschel U: Genomic mining for novel FADH(2)dependent halogenases in marine sponge-associated microbial consortia. Mar Biotechnol (NY) 2013, 15:63-72. 